\title{
High Levels of Circulating Endothelial Progenitor Cells Are Associated with Acrotism in Patients with Takayasu Arteritis
}

\author{
Şakir Özgür Keşkek ${ }^{a}$ Emine Duygu Bozkırlı-Ersözlüb Ilknur Kozanogluc \\ Ahmet Eftal Yücel ${ }^{b}$ \\ a Department of Internal Medicine, Numune Training and Research Hospital, and Departments of \\ ${ }^{b}$ Rheumatology and ${ }^{\mathrm{C}}$ Physiology, Başkent University School of Medicine, Adana, Turkey
}

\section{Key Words}

Acrotism · C-reactive protein - Endothelial progenitor cells . Erythrocyte sedimentation rate $\cdot$ Takayasu arteritis

\begin{abstract}
Objectives: To investigate the association between endothelial progenitor cells (EPCs) and Takayasu arteritis (TA). Subjects and Methods: A total of 39 subjects were included in this study: 12 subjects had been diagnosed with active TA, 11 had active Behçet disease (BD), and 16 were healthy controls. The EPCs, erythrocyte sedimentation rate (ESR), and C-reactive protein (CRP) levels of all the subjects were measured. MedCalc 15.8 software (MedCalc, Belgium) was used for all statistical analyses. Results: The level of EPCs was higher in TA patients $(4.25 \pm 2.56)$ than in the BD group $(2.27 \pm 2.0)$ and the healthy controls $(2.12 \pm 1.2)(p=0.015)$. TA patients with acrotism $(n=4)$ had higher levels of EPCs compared to TA patients without acrotism $(n=8)(6.50 \pm 1.73$ vs. $3.12 \pm 2.16$, $p=0.02$ ). A positive correlation was found between EPCs and the ESR ( $r=0.723, p=0.0079)$ and between EPCs and CRP in patients with TA $(r=0.769, p<0.0034)$. Conclusion: High levels of circulating EPCs were correlated with the CRP level and the ESR in patients with TA. These cells could be a marker for acrotism and inflammation in patients with TA.
\end{abstract}

(c) 2016 S. Karger AG, Basel

\begin{tabular}{ll}
\hline KARGER & (c) 2016 S. Karger AG, Basel \\
$\begin{array}{l}\text { E-Mail karger@karger.com } \\
\text { www.karger.com/mpp }\end{array}$ & $\begin{array}{l}\text { This is an Open Access article licensed under the terms of the } \\
\text { Creative Commons Attribution-NonCommercial 3.0 Un- } \\
\text { ported license (CC BY-NC) (www.karger.com/OA-license), } \\
\text { applicable to the online version of the article only. Distribu- } \\
\text { tion permitted for non-commercial purposes only. }\end{array}$
\end{tabular}

\section{Introduction}

Takayasu arteritis (TA) is a rare, chronic, systemic, inflammatory vasculitis that involves large- and medium-sized vessels $[1,2]$. It predominantly occurs in females and its etiology is unknown [1]. The clinical presentation of TA varies according to the localization and the extent of the involved vessels [1]. Therefore, different clinical symptoms may be seen, ranging from fever and malaise to hypertension and ischemic symptoms, such as claudication and angina. Pulses are commonly absent in the involved vessels, particularly in the subclavian artery $[1,2]$. According to histopathological investigations, the histologic characteristic of TA is a cell-mediated autoimmune disorder associated with cellular infiltration of the macrophages and CD4+ and CD8+ T cells $[3,4]$. TA has 2 phases: early systemic phase and late phase. Nonspecific acute inflammatory features are found in the early systemic phase, which is characterized by the involvement of the adventitial vasa vasorum and the cellular infiltration of the tunica media $[5,6]$. Intimal hyperplasia occurs due to the fibrosis of the tunica media and intima during this period. The late phase is characterized by the destruction of the elastic tissue and marked fibrosis, which leads to stenosis, occlusion, or aneurysm in the artery $[5,7]$. 
Circulating endothelial progenitor cells (EPCs) are bone marrow-derived, immature cells that take part in neovascularization and vascular homeostasis; they are composed of several cell types, including hematopoietic and mesenchymal stem cells [8]. The level of circulating EPCs is low in normal medical conditions, but rapidly increases in the case of vascular injury and tissue ischemia. In response to pathological stimulation resulting from vascular injury or tissue ischemia, the EPCs migrate to the peripheral circulation and develop into mature endothelial cells [9]. In this study, we aimed to investigate the association between EPCs and TA.

\section{Material and Methods}

Study Design and Ethical Approval

This cross-sectional cohort study was carried out in the Rheumatology Clinics, Adana Training Hospital, Başkent University School of Medicine, Turkey, from March 5, 2011, to July 1, 2011. The Hospital Ethics Committee approved the study and written informed consent was obtained from all subjects. All procedures were in accordance with the Good Clinical Practice standards, the ethical standards of the Responsible Committee on Human Experimentation, and the Helsinki Declaration of 1975, as revised in 2008.

\section{Population}

A total of 39 subjects (13 males and 26 females), with a minimum age of 18 years were included in this study. The study group consisted of 12 patients with active TA, and the control group consisted of 16 healthy subjects. We also enrolled 11 patients with active Behçet disease (BD) as a positive control group. Additionally, TA patients were divided into 2 subgroups according to the presence $(n=8)$ or absence $(n=4)$ of a pulse.

The exclusion criteria were chronic diseases other than TA and $\mathrm{BD}$; medical conditions that could cause inflammation or ischemia and effect EPC levels, such as malignancy, infections, recent surgery, or trauma; and breastfeeding and pregnant women. The medical histories and conditions of the participants were carefully ascertained by physicians (Ş.O.K., E.D.E.-B., and A.E.Y.). Patients with TA fulfilled the proposed classification criteria of the American College of Rheumatology for TA [10]. The disease activity of the patients with TA was assessed with Kerr's criteria [11]. Acrotism was defined as absence of a pulse in patients with TA (pulselessness). The diagnosis of $\mathrm{BD}$ was based on new international criteria [12]. Activity of $\mathrm{BD}$ was determined according to the activity index of the Behçet's Disease Research Committee of Japan [13].

\section{Blood Sample Collection and Analysis}

A peripheral blood sample was drawn using a 21-gauge needle into a tube containing ethylenediaminetetraacetic acid (EDTA) as an anticoagulant. The blood samples were kept at $4^{\circ} \mathrm{C}$ and analyzed using flow cytometry within $4 \mathrm{~h}$ of venesection. Peripheral whole blood cells were prepared by a lyse/wash procedure and were then evaluated using a flow cytometer (FACSCantoII; Becton Dickinson, San Jose, CA, USA). The use of this procedure minimizes cell loss, making it possible to measure all EPCs in the blood samples. A multistep manual technique was used to detect and quantify EPCs. An assessment of a minimum of 400,000 cells/peripheral blood sample was considered informative. Anti-CD146 PE, antiCD31 FITC, anti-CD45 APC- Cy7, and anti-CD34 PE- Cy7 monoclonal antibodies were used for the detection of EPCs. All monoclonal antibodies were from Becton Dickinson BioScience (San Jose, California, USA). The Cell-Dyn 3700 Hematology Analyzer (Abbott Laboratories, Chicago, IL, USA) was used for white blood cell counts. Cells were identified as EPCs if they were CD146+/ CD31+/CD45-/CD34+ cells (Fig. 1). Flow cytometry data were analyzed with DIVA software (Becton Dickinson). Nonviable cells, platelets, debris, and nonspecific binding were excluded from the analysis by isotopic control and consecutive gating $[14,15]$.

The ESR and CRP were measured in all patients and the levels were determined using the Westergreen method and immunoturbidimetry, respectively.

\section{Statistical Analysis}

MedCalc 15.8 software (MedCalc, Ostend, Belgium) was used for all statistical analyses, and the data are reported as means \pm SD. The Kolmogorov-Smirnov test was used to show the normal distribution of quantitative measurements, a $\chi^{2}$ test was used to test the statistical significance of the differences in frequencies, and ANOVA or Kruskal-Wallis tests were used for the comparison of the quantitative measurements (EPCs, ESR, CRP, and age) between more than 2 groups. A post hoc test (using Student-Newman-Keuls) was performed for pairwise comparison of subgroups when the ANOVA test was positive ( $p$ less than the selected significance level).

A Student $t$ test was used for the comparison of the quantitative measurements (disease duration) between the TA and $\mathrm{BD}$ groups. Additionally, a $t$ test was performed for the comparison of the subgroups (TA patients with or without a pulse) according to the EPCs, CRP, and ESR. The correlation coefficient was used to analyze the degree of association between the EPCs and CRP, and between EPCs and ESR (Pearson correlation coefficient $(r)$ with $p$ value and 95\% CI for $r$ ). Multiple regression analysis (backward method) was used to analyze the relationship between a dependent variable (EPCs) and 1 or more independent variables (age, sex, smoking status, disease duration, CRP, and ESR). According to the backward method, the model enters all variables into the model and then removes the nonsignificant variables sequentially. Age, sex, smoking status, disease duration, and CRP were not included in the model due to the very low tolerance of the variables $(<0.0001)$. Power analysis was performed for the sample size to have $80 \%$ power with $5 \%$ type 1 error.

The probability of making a type I error ( $\alpha$, significance) is 0.05 in all tests.

\section{Results}

The mean age of all the subjects was $32.8 \pm 8.0$ years. The mean ages of the $\mathrm{TA}, \mathrm{BD}$, and healthy groups were $32.7 \pm 6.5,31.9 \pm 8.5$, and $33.6 \pm 9.0$ years, respectively $(p=0.866)$. The clinical manifestations of the groups are shown in Table 1 while the distribution of vascular 

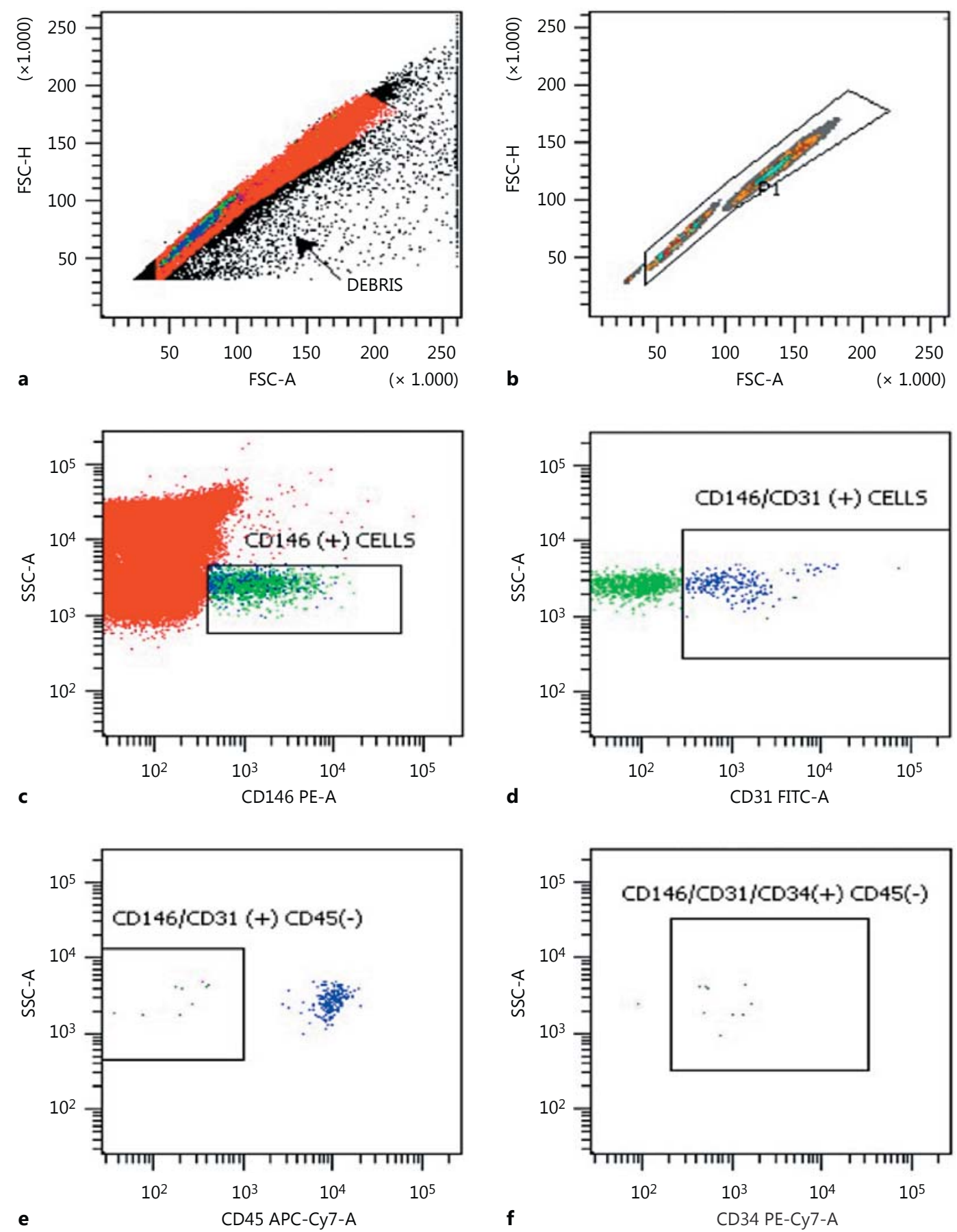

Fig. 1. Analysis strategy for the identification of circulating endothelial cells by using flow cytometry: immunophenotyping of FSC$\mathrm{H}$ and FSC-A (a), FSC-H and FSC-A (b), SSC-A and CD146 PE-A (c), SSC-A and CD31 FITC-A (d), SSC-A and CD45 APC-Cy7-A (e), and SSC-A and CD34 PE-Cy7-A (f). Gating and quantification of endothelial cells (nonviable cells, platelets, debris, and nonspe-

cific binding) were excluded in $\mathbf{a}$ and $\mathbf{b}$. FSC-H, forward scatter height; FSC-A, forward scatter area; SSC-A, side scatter area; PEA, phycoerythrin area; FITC-A, fluorescein isothiocyanate area; APC-Cy7-A, allophycocyanin-cyanin7; PE-Cy7-A, phycoerythrin area.

Keşkek/Bozkırl1-Ersözlü/Kozanoglu/ Yücel 
Table 1. Clinical characteristic of the groups

\begin{tabular}{llll}
\hline Clinical manifestations & $\begin{array}{l}\text { TA } \\
(n=12)\end{array}$ & $\begin{array}{l}\text { BD } \\
(n=11)\end{array}$ & $\begin{array}{l}\text { Healthy } \\
(n=16)\end{array}$ \\
\hline Hypertension & $8(66.6)$ & $3(27.7)$ & - \\
Malaise & $7(58.3)$ & $5(45.4)$ & - \\
Claudication & $5(41.6)$ & - & - \\
Acrotism & $4(33.3)$ & - & - \\
Bruits & $4(33)$ & $1(9)$ & - \\
Arthralgia & $4(33)$ & $5(45.4)$ & - \\
Absence of blood pressure & $3(25)$ & - & - \\
Central nervous system & $3(25)$ & $2(18.1)$ & - \\
Cutaneous & $2(16.6)$ & $1(9)$ & - \\
Angina pectoris & $1(8.3)$ & - & - \\
Ocular involvement & $1(8.3)$ & $4(36.3)$ & - \\
\hline
\end{tabular}

Data are presented as $n(\%)$. TA, Takayasu arteritis; BD, Behçet disease.
Table 2. Vascular involvement of patients with TA

\begin{tabular}{ll}
\hline Vascular involvement & $n(\%)$ \\
\hline Left carotid artery & $6(50)$ \\
Left subclavian artery & $5(41.6)$ \\
Right carotid artery & $4(33.3)$ \\
Right subclavian artery & $1(8.3)$ \\
Descending aorta & $1(8.3)$ \\
Ascending aorta & $1(8.3)$ \\
Abdominal aorta & $1(8.3)$ \\
Thoracic aorta & $1(8.3)$ \\
Pulmonary artery & $1(8.3)$ \\
Brachial artery & $1(8.3)$ \\
Left renal artery & $1(8.3)$ \\
Right renal artery & $1(8.3)$ \\
Right coronary artery & $1(8.3)$ \\
\hline
\end{tabular}

Table 3. Comparison of the groups according to the demographic data and biochemical measures

\begin{tabular}{|c|c|c|c|c|}
\hline & $\begin{array}{l}\text { TA } \\
(n=12)\end{array}$ & $\begin{array}{l}\mathrm{BD} \\
(n=11)\end{array}$ & $\begin{array}{l}\text { Healthy subjects } \\
(n=16)\end{array}$ & $p$ values \\
\hline Age, years & $32.7 \pm 6.5(30.0)$ & $31.9 \pm 8.5(30.0)$ & $33.6 \pm 9.0(31.5)$ & 0.866 \\
\hline Smoking & $2(16.7)$ & $2(18.2)$ & $4(25.0)$ & 0.893 \\
\hline $\mathrm{ESR}, \mathrm{mm} / \mathrm{h}$ & $20.7 \pm 14.9(16.5)$ & $15.6 \pm 12.6(10.0)$ & $9.1 \pm 3.7(8.5)$ & 0.028 \\
\hline $\mathrm{CRP}, \mathrm{mg} / \mathrm{L}$ & $5.1 \pm 3.5(3.9)$ & $7.3 \pm 10.6(3.0)$ & $1.0 \pm 0.3(1.0)$ & $<0.001$ \\
\hline Disease duration, months & $73.7 \pm 67.2(60.5)$ & $31.1 \pm 19.7(40.0)$ & - & 0.056 \\
\hline
\end{tabular}

Data are presented as means \pm SD (median) or $n(\%)$. TA, Takayasu arteritis; BD, Behçet disease.

involvement in TA patients is shown in Table 2. Demographic characteristics and biochemical measurements of the groups are shown in Table 3. The mean EPC levels were $4.25 \pm 2.56$ cells $/ \mu \mathrm{L}$ in the patients with TA, $2.27 \pm$ 2.0 cells $/ \mu \mathrm{L}$ in the patients with $\mathrm{BD}$, and $2.12 \pm 1.2$ cells/ $\mu \mathrm{L}$ in the healthy subjects. The EPC levels were higher in patients with TA and the difference was statistically significant ( $p=0.015$; Table 3 ).

The mean levels of ESR were $20.7 \pm 14.9 \mathrm{~mm} / \mathrm{h}$ (TA), $15.6 \pm 12.6 \mathrm{~mm} / \mathrm{h}(\mathrm{BD})$, and $9.1 \pm 3.7 \mathrm{~mm} / \mathrm{h}$ (healthy). Similarly, the mean ESRs of the groups were statistically different $(p=0.028)$. Patients with TA had the highest ESR measurements.

The CRP levels of the TA, BD, and healthy groups were $5.1 \pm 3.5,7.3 \pm 10.6$, and $1.0 \pm 0.3 \mathrm{mg} / \mathrm{L}$, respectively. The difference was statistically significant $(p=0.001)$. The dis- ease durations of the TA group and the $\mathrm{BD}$ group were comparable (73.7 \pm 67.2 months vs. $31.1 \pm 19.7$ months; $p=0.056)$.

TA patients with acrotism $(\mathrm{n}=4)$ had higher EPCs compared to TA patients with a palpable pulse $(\mathrm{n}=8)$ $(6.50 \pm 1.73$ vs. $3.12 \pm 2.16$ cells $/ \mu \mathrm{L}, p=0.02)$. Additionally, ESR and CRP levels were also higher in TA patients with acrotism (ESR: $36.0 \pm 14.4$ vs. $13.1 \pm 7.7 \mathrm{~mm} / \mathrm{h}, p=$ 0.004; CRP: $7.9 \pm 5.1$ vs. $3.8 \pm 1.6 \mathrm{mg} / \mathrm{L}, p=0.012$; Table 4 ).

According to the Pearson correlation analyses, a positive correlation was found between EPCs and ESR ( $r=$ $0.723, p=0.0079)$ and between EPCs and CRP in patients with TA $(r=0.769, p<0.0034)$, while there was no correlation in BD patients $(r=0.110, p=0.746 ; r=0.200$, $p=0.554$, respectively). The correlations between EPCs, ESR, and CRP in the TA patients are shown in Figure 2. 
Table 4. Comparisons between TA patients with or without pulselessness

\begin{tabular}{lccc}
\hline & $\begin{array}{l}\text { TA patients with acrotism } \\
(n=4)\end{array}$ & $\begin{array}{l}\text { TA patients without } \\
\text { acrotism }(n=8)\end{array}$ & $p$ \\
\hline Age, years & $34.2 \pm 6.8(33.5)$ & $32.0 \pm 6.7(30.0)$ & 0.594 \\
Female & $4(100)$ & $5(62.5)$ & 0.490 \\
Smoking & $1(25)$ & $1(12.5)$ & 0.625 \\
ESR, mm/h & $36.0 \pm 14.4(31)$ & $13.1 \pm 7.7(11)$ & 0.004 \\
CRP, mg/L & $7.9 \pm 5.1(7.7)$ & $3.8 \pm 1.6(3.7)$ & 0.012 \\
EPCs, cells/ $\mu \mathrm{L}$ & $6.50 \pm 1.73(6.5)$ & $3.12 \pm 2.16(3.5)$ & 0.02 \\
Disease duration, months & $56.8 \pm 43.3(65.0)$ & $107.5 \pm 99.5(47.5)$ & 0.233 \\
\hline
\end{tabular}

Data are presented as means \pm SD (median) or $n(\%)$. TA, Takayasu arteritis.

Multiple regression analysis (backward method) was performed with EPCs as a dependent variable and with age, sex, smoking status, disease duration, ESR, and CRP as independent variables. ESR was independently associated with EPC levels in TA patients $(p=0.007)$.

\section{Discussion}

In this study, patients with TA had high levels of EPCs and a positive correlation between EPCs and ESR, and between EPCs and CRP. Moreover, the EPC levels of the TA patients with acrotism were higher than without acrotism. The association between EPCs and other rheumatic diseases, such as rheumatoid arthritis, systemic lupus erythematosus, systemic sclerosis, and $\mathrm{BD}$, has been investigated in previous studies. Low levels of EPCs were reported in these studies [16-19]. On the other hand, the association between EPCs and TA was investigated only in a few studies and high levels of EPCs were reported by them [20, 21]. Dogan et al. [21] reported high levels of EPCs in active TA patients. In this study they compared active TA patients with inactive TA patients and healthy controls. In another study, Dang et al. [20] concluded that circulating endothelial cells were significantly higher in patients with aortoarteritis at active stages than in those at inactive stages. However, this study was not controlled and EPCs were not studied. Additionally, neither study investigated the association between EPCs and acrotism in TA patients.

The high levels of EPCs in TA patients with acrotism could be due to ischemia caused by stenosis or occlusion; otherwise, the level of circulating EPCs is generally low in normal medical conditions, but rapidly increases in the

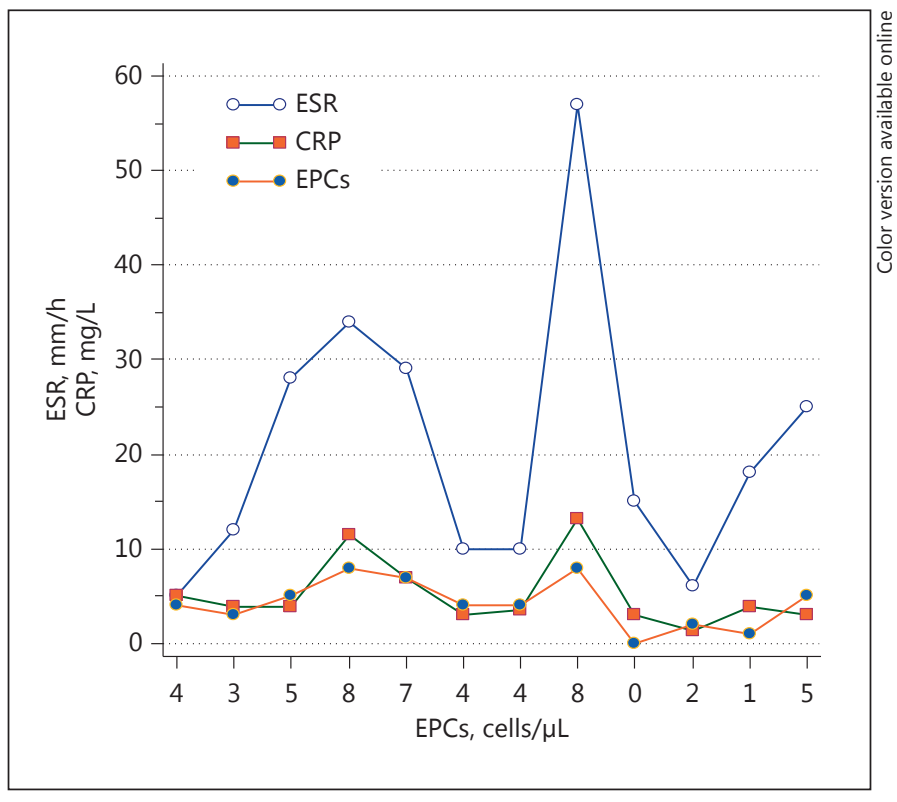

Fig. 2. Comparison of EPCs, ESR, and CRP. The horizontal axis shows the EPCs (cells/ $\mu \mathrm{L}$ ) levels while the vertical axis shows the ESR $(\mathrm{mm} / \mathrm{h})$ and CRP $(\mathrm{mg} / \mathrm{L})$ levels for each case, sequentially. The correlation between EPCs and ESR, and between EPCs and $\mathrm{CRP}$, can be seen more clearly in this figure.

case of vascular injury and tissue ischemia $[8,9]$. It has been shown that development of vessel wall inflammation due to the lymphocytic infiltration in the early phase and destruction of elastic tissue during the late phase [22] of the disease leads to stenosis, occlusion, dilatation, and aneurism in TA patients $[6,7]$.

In the present study, EPC levels were high in TA patients compared to BD patients. BD is both a systemic 
vasculitis and chronic inflammatory disease, as is TA [23]. However, high EPC levels in TA patients may be associated with specific factors related with the histopathology of TA that are different from BD. TA is a progressive form of vasculitis with ongoing inflammation. Endothelial injury and endothelial repair occur in combination [21]. EPCs increase in case of ongoing or acute inflammation while they decrease in case of chronic inflammatory state $[24,25]$. Further reinforcing this link, Fadini et al. [19] reported low levels of EPC in patients with BD in their study. In another study, Bozkirli et al. [26] studied EPCs in BD patients and reported that the levels of EPCs were not high compared to levels in the healthy controls.

The CRP and ESR levels of TA patients were higher compared to healthy controls in the present study. Moreover, they were positively correlated with EPCs levels in TA patients. In accordance with this link, Dang et al. [20] reported a positive correlation between circulating endothelial cells and ESRs in active aortoarteritis patients. Additionally, Dogan et al. [21] reported a positive correlation between EPCs and Indian Takayasu Activity Score CRP levels in active TA patients. The progressive form of vasculitis with ongoing inflammation that results in vessel injury can lead to high levels of CRP and ESR [21]. CRP plays a role in mediating vascular disease and acti- vates the classical complement signaling cascade, which plays a key role in neointima formation in injured vessels [27]. Additionally, we have reported higher levels of CRP and ESR in TA patients with acrotism. This result might occur due to the increased vessel inflammation in TA patients with acrotism.

This study had some limitations. First, vascular endothelial growth factor receptor-2 was not used to characterize EPCs because it is restricted to endothelial cells and their progenitors. Second, both TA and BD patients were receiving treatment during the study period so EPC levels might be affected. Fourth, due to the study design (crosssectional cohort), EPCs levels were measured only once and they were not measured after a period of treatment.

\section{Conclusion}

In this study, patients with TA had high levels of EPCs. The TA patients with acrotism had higher levels of EPCs than those without. The EPCs were correlated with acute phase reactants. These findings indicate that EPCs could provide information about vascular involvement in patients with TA, in particular for patients with the absence of a pulse. EPCs might also show acute inflammation and active disease in patients with TA.

\section{References}

1 Langford AC, Fauci AS: The vasculitis syndromes; in Longo DL, et al (eds): Harrison's Principles of Internal Medicine. New York, McGraw Hill, 2015, vol 19, pp 2189-2190.

2 Stone JH: Systemic vasculitis; in Goldman L, et al (eds): Cecil Medicine. Philadelphia, Elsevier, 2015, vol 24, pp 1720-1723.

3 Numano F: Takayasu's arteritis: clinical aspects; in Hoffman GS, et al (eds): Inflammatory Diseases of Blood Vessels. New York, Marcel Dekker, 2002, p 455.

4 Noguchi S, Numano F, Gravanis MB, et al: Increased levels of soluble forms of adhesion molecules in Takayasu arteritis. Int J Cardiol 1998;66(suppl 1):S23-S33.

5 Numano F, Kobayashi Y: Takayasu arteritis - beyond pulselessness. Intern Med 1999;38: 226-232.

6 Gravanis MB: Giant cell arteritis and Takayasu aortitis: morphologic, pathogenetic and etiologic factors. Int J Cardiol 2000;75:S21-S33.

7 Andrews J, Mason JC: Takayasu's arteritis recent advances in imaging offer promise. Rheumatology 2007;46:6-15.
8 Hristov M, Weber C: Endothelial progenitor cells: characterization, pathophysiology, and possible clinical relevance. J Cell Mol Med 2004;8:498-508.

9 Masuda H, Kalka C, Takahashi T: Estrogenmediated endothelial progenitor cell biology and kinetics for physiological postnatal vasculogenesis. Circ Res 2007;101:598-606.

10 Arend WP, Michel BA, Bloch DA, et al: The American College of Rheumatology 1990 criteria for the classification of Takayasu arteritis. Arthritis Rheum 1990;33:1129-1134.

11 Kerr GS, Hallahan CW, Giordano J, et al: Takayasu arteritis. Ann Intern Med 1994;120: 919-929.

12 International Team for the Revision of the International Criteria for Behçet's Disease (ITRICBD): The International Criteria for $\mathrm{Be}$ hcet's Disease (ICBD): a collaborative study of 27 countries on the sensitivity and specificity of the new criteria. J Eur Acad Dermatol Venereol 2014;28:338-347.

13 Kurokawa MS, Suzuki N: Behçet's disease. Clin Exp Med 2004;3:10-20.
14 Ozdogu H, Sozer O, Boga C, et al: Flow cytometric evaluation of circulating endothelial cells: a new protocol for identifying endothelial cells at several stages of differentiation. Am J Hematol 2007;82:706-711.

15 Bogoslovsky T, Maric D, Gong Y, et al: Preservation and enumeration of endothelial progenitor and endothelial cells from peripheral blood for clinical trials. Biomark Med 2015;9: 625-637.

16 Rüger B, Giurea A, Wanivenhaus AH, et al: Endothelial precursor cells in the synovial tissue of patients with rheumatoid arthritis and osteoarthritis. Arthritis Rheum 2004;50: 2157-2166.

17 Westerweel PE, Luijten RK, Hoefer IE, et al: Haematopoietic and endothelial progenitor cells are deficient in quiescent systemic lupus erythematosus. Ann Rheum Dis 2007;66: 865-870.

18 Kuwana M, Okazaki Y, Yasuoka H, et al: Defective vasculogenesis in systemic sclerosis. Lancet 2004;364:603-610. 
19 Fadini GP, Tognon S, Rodriguez L: Low levels of endothelial progenitor cells correlate with disease duration and activity in patients with Behçet's disease. Clin Exp Rheumatol 2009; 27:814-821.

20 Dang A, Wang B, Li W, et al: Plasma endothelin-1 levels and circulating endothelial cells in patients with aortoarteritis. Hypertens Res 2000;23:541-544.

21 Dogan S, Piskin O, Solmaz D, et al: Markers of endothelial damage and repair in Takayasu arteritis: are they associated with disease activity? Rheumatol Int 2014;34:1129-1138.
22 Chaudhry MA, Latif F: Takayasu's arteritis and its role in causing renal artery stenosis. Am J Med Sci 2013;346:314-318.

23 Mendoza-Pinto C, Garcia-Carrasco M, Jimenez-Hernandez M, et al: Etiopathogenesis of Behcet's disease. Autoimmun Rev 2010; 9:241-245.

24 Avouac J, Uzan G, Kahan A, et al: Endothelial progenitor cells and rheumatic disorders. Joint Bone Spine 2008;75:131-137.
25 Fujii H, Li Sh, Szmitko PE, et al: C-reactive protein alters antioxidant defenses and promotes apoptosis in endothelial progenitor cells. Arterioscler Thromb Vasc Biol 2006;26: 2476-2482.

26 Bozkirli ED, Keșkek SÖ, Kozanoğlu I, et al: High levels of endothelial progenitor cells can be associated with thrombosis in patients with Behçet's disease. Clin Exp Rheumatol 2014; 32:S49-S53.

27 Hage FG, Oparil S, Xing D, et al: C-reactive protein-mediated vascular injury requires complement. Arterioscler Thromb Vasc Biol 2010;30:1189-1195. 